Vietnam Journal of Mechanics, VAST, Vol. 27, No. 4 (2005), pp. 229-239

\title{
STORM WAVE MODELING WITH SWAN COMPARISON OF MEASUREMENT DATA AND MODELING RESULTS FOR THE STORM MUIFA $11 / 2004$
}

\author{
Nguyen Manh Hung ${ }^{1}$, Do Le Thuy ${ }^{2}$ and Duong Cong Dien ${ }^{1}$ \\ ${ }^{1}$ Institute of Mechanics \\ ${ }^{2}$ National Center for Hydro-Meteorological Forecast (NCHMF)
}

\begin{abstract}
With the average of 4-5 storms hitting the Vietnamese coastline every year, our country is suffering from great damage of infrastructures and lost of human life. Most storms induce significant waves which, especially in the coastal zones, can destroy houses, coastal structures and move large amounts of sand from beaches to offshore resulting in shoreline erosion. Therefore modeling of storm waves is an important task of engineers, scientists, weather forecasting specialists of our country. In order to meet the need of mitigation storm effects, to improve the storm wave forecasting capability in general and to study the coastal evolution in the Red River Delta (RRD) in particular, the authors have developed the SWAN model for the storm wave calculation in the East Sea. In the paper some formulations of the model has been used to get the best agreement with the measured wave field in the storm MUTFA 11/2004. The wind and wave data at the oil platform MSP1 and wave height field over the sea were used to compare the model results. The obtained results afford the promising of using the SWAN model in research and weather forecast.
\end{abstract}

\section{INTRODUCTION}

The main effects of storms causing destroys of any construction on their propagating way is strong winds, waves, storm surges and currents. Beside this, storms also cause heavy rainfall with long duration resulting in severe flooding in the delta areas. In the coastal zones these effects cause the shore line retreat, flood and breaches. RRD is a low water lying area which is very sensitivity to all the about mentioned effects of storms. The storm Pat, which hit the coast of the Nam Dinh and Thai Binh provinces on October 23, 1988 has damaged many houses, made 500,000 homeless and killed more than 90 persons. Other significant effect is the beach and coastal line evolution induced by this storm. The factors influencing coastal erosion caused by storms are tabulated in the table 1 . It is clear that erosion tends to increase when wave height is high, wave period is low, beach slope is high, storm surge is high, etc. Thus, modeling of storm waves is essential for both natural disaster mitigation and the study of coastline evolution.

The present work is aimed at application of SWAN wave model to calculate wave fields in storms MUIFA 11/2004. The wind data from Japan Meteorological Agency (JMA) were use as input for the wave model. Wave field for the whole area of the sea from SEAMOS (South East Asian Meteorological and Oceanography Study- http://www.oceanweather.com) and especially wave recorded at the oil platform MSP1 have been used to compare the calculated results. 


\section{BASIC THEORY OF SWAN MODEL}

As the third generation wave model, SWAN is characterized by the crucial role of the nonlinear wave-wave interaction (which is predominated in the storm areas) and the freedom from any a priori constraints imposed on the spectral form during the process of wave evolution while the later condition is not fulfilled in the first and second generation models. The last versions of the model have been improved as the deep water alone wave model and with the including of diffraction of coastal construction (version 40.41, 2005 $[3])$.

Table 1. Factors influencing erosion caused by storms [1]

\begin{tabular}{|l|l|l|}
\hline Main Factors & Sub factors & $\begin{array}{l}\text { Increased tendency toward erosion } \\
\text { With (high/low) values }\end{array}$ \\
\hline \multirow{5}{*}{ Storm processes } & $\begin{array}{l}\text { Wind velocity } \\
\text { Wind direction }\end{array}$ & $\begin{array}{l}\text { High } \\
\text { Variable }\end{array}$ \\
\cline { 2 - 3 } & Wave height & High \\
\cline { 2 - 3 } & Wave period & Low \\
\cline { 2 - 3 } & Wave steepness & High \\
\cline { 2 - 3 } Beach & Long shore current & High \\
\cline { 2 - 3 } & Storm duration & High \\
\hline & Sediment size & Low (to silt size) \\
\cline { 2 - 3 } & Degree of lithification & Low \\
\cline { 2 - 3 } & $\begin{array}{l}\text { Morphology } \\
\text { Slope } \\
\text { Rhythmic topography }\end{array}$ & High \\
& Tide state & High \\
\hline \multirow{2}{*}{ Water level } & Storm surge & High \\
\hline
\end{tabular}

\subsection{Action balance equation}

In SWAN the evolution of the wave spectrum is described by the spectral action balance equation in Cartesian coordinates as:

$$
\frac{\partial}{\partial t} N+\frac{\partial}{\partial x} C_{x} N+\frac{\partial}{\partial y} C_{y} N+\frac{\partial}{\partial \sigma} C_{\omega} N+\frac{\partial}{\partial \theta} C_{\theta} N=\frac{S}{\sigma},
$$

where $N(\sigma, \theta)$ is action density spectrum $(N(\sigma, \theta)=E(\sigma, \theta) / \sigma), C_{x}, C_{y}$ and $C_{\theta}$ are propagation velocities in $x, y$ space and $\theta$ direction respectively, $\sigma$ is wave frequency, $\theta$ is wave direction, $E(\sigma, \theta)$ is wave energy, $S(\sigma, \theta)$ is the source term.

The first term in the left side represents the local rate of change of action density in time, the second and third term represent propagation of action in space. The fourth term represents shifting of relative frequency due to variations in depth and currents. The fifth term represents depth induced and current-induced refraction. The $S$ term at the right side includes the effects of generation, dissipation and nonlinear wave-wave interaction. SWAN also has its option in spherical coordinates [3]. 
The source term is very important for any wave model and it distinguishes the advantage of each model. This term in SWAN is formulated as follow:

+ Wind input $-S_{\text {in }}$

A resonance mechanism of Phillips and a feed-back mechanism of Miles are described as the sum of linear and exponential wave's growth under wind stresses:

$$
S_{i n}(\sigma, \theta)=A+B E(\sigma, \theta)
$$

where: $A$ is the linear and $B$ is the exponential waves growth.

+ Dissipation of wave energy - $S_{d s}$

In the deep water the dissipation of wave energy is considered as white capping - the whitecapping wave breaking caused by the exceeding of the maximum wave steepness.

$$
S_{d s, w}(\sigma, \theta)=-\Gamma \tilde{\sigma} \frac{k}{\tilde{k}} E(\sigma, \theta)
$$

where $\tilde{\sigma}$ and $\tilde{k}$ denote the mean frequency and the mean wave number. The coefficient $\Gamma$ depends on the overall wave steepness.

- Bottom friction

The empirical model of JONSWAP, the drag model of Collin and the eddy-viscosity model of Madsen [3] have been used in SWAN to calculate the bottom friction dissipating wave energy.

$$
S_{d s, b}(\sigma, \theta)=-C_{\text {bottom }} \frac{\sigma^{2}}{g^{2} \sinh ^{2}(k d)} E(\sigma, \theta),
$$

where $C_{b o t t o m}$ is the bottom friction coefficient, $\mathrm{d}$ is the water depth.

- Depth-induced wave breaking

In SWAN the energy dissipation due to the depth-induced wave breaking is calculated using the bore-based model of Battjes and Janssen. The mean rate of energy dissipation per unit horizontal area due to wave breaking $D_{\text {tot }}$ is:

$$
D_{\text {tot }}=-\frac{1}{4} \alpha_{B J} Q_{b}\left(\frac{\bar{\sigma}}{2 \pi}\right) H_{m}^{2}
$$

in which $\alpha_{B J}=1$ and $Q_{b}$ is the fraction of breaking wave and $\mathrm{H}_{m}$ if the maximum wave height can exist at the given depth.

The dissipation for a spectral component per unit time is:

$$
S_{d s, b r}(\sigma, \theta)=D_{\text {tot }} \frac{E(\sigma, \theta)}{E_{\text {tot }}}
$$

where $E_{\text {tot }}$ is the total wave energy before breaking.

+ Nonlinear wave-wave interactions

- Quadruplet wave-wave interactions

The quadruplet wave-wave interactions are computed with the Discrete Interaction Approximation (DIA), proposed by Hasselmann. In these interactions two quadruplets of wave numbers are considered with the following frequencies:

$$
\begin{aligned}
& \sigma_{1}=\sigma_{2}=\sigma, \\
& \sigma_{3}=\sigma_{2}(1+\lambda)=\sigma^{+}, \\
& \sigma_{4}=\sigma_{2}(1-\lambda)=\sigma^{-},
\end{aligned}
$$


where $\lambda$ is a constant coefficient set equal to 0.25 .

With this discrete interaction approximation, the source term $S_{n l 4}(\sigma, \theta)$ is given by:

$$
S_{n l 4}(\sigma, \theta)=S_{n l 4}^{*}(\sigma, \theta)+S_{n l 4}^{* *}(\sigma, \theta),
$$

where $S *_{n l 4}$ refers to the first quadruplet and $S_{n l 4}^{* *}$ to the second one and:

$$
S_{n l 4}^{*}(\sigma, \theta)=2 \delta S_{n l 4}\left(\alpha_{1}^{\prime} \sigma, \theta\right)-\delta S_{n l 4}\left(\alpha_{2} \sigma, \theta\right)-\delta S_{n l 4}\left(\alpha_{3} \sigma, \theta\right),
$$

in which $\alpha_{1}=1, \alpha_{2}=(1+\lambda)$ and $\alpha_{3}=(1-\lambda)$.

- Triad wave-wave interactions

The Lumped Triad Approximation (LTA) of Eldeberky is used in SWAN in each spectral direction:

$$
S_{n l 3}(\sigma, \theta)=S_{n l 3}^{-}(\sigma, \theta)+S_{n l 3}^{+}(\sigma, \theta),
$$

where:

$$
S_{n l 3}^{+}(\sigma, \theta)=\max \left\{0, \alpha_{E B} 2 \pi c c_{g} J^{2}|\sin \langle\beta\rangle|\left\{E^{2}(\sigma / 2, \theta)-2 E(\sigma / 2, \theta) E(\sigma, \theta)\right\}\right\},
$$

and:

$$
S_{n l 3}^{-}(\sigma, \theta)=-2 S_{n l 3}^{+}(2 \sigma, \theta),
$$

in which $\alpha_{E B}$ is a tunable proportionality coefficient and $\beta$ is approximated as:

$$
\beta=-\frac{\pi}{2}+\frac{\pi}{2} \tanh \left(\frac{0.2}{U r}\right),
$$

with Ursell number $U_{r}$ :

$$
U r=\frac{g}{8 \sqrt{2} \pi^{2}} \frac{H_{s} \bar{T}^{2}}{d^{2}},
$$

where $\bar{T}=2 \pi / \bar{\sigma}$ and $J$ is the interaction coefficient determined by Madsen and Sorensen.

In a $1 \mathrm{D}$ case the computation of the wave induced set up is based on the vertically integrated momentum balance between the wave force and the hydrostatic pressure gradient.

$$
F_{x}+g d \frac{\partial \bar{\eta}}{\partial x}=0
$$

where $d$ is the total depth and $\eta$ is the mean surface elevation (including the wave induced set up).

In $2 \mathrm{D}$ case the momentum balance equation is:

$$
\frac{\partial F_{x}}{\partial x}+\frac{\partial F_{y}}{\partial y}+\frac{\partial}{\partial x}\left(g d \frac{\partial \varsigma}{\partial x}\right)+\frac{\partial}{\partial y}\left(g d \frac{\partial \varsigma}{\partial y}\right)=0
$$

\subsection{Numerical implementation}

The integration of the action balance equation has been implemented in SWAN with finite difference schemes in all file dimensions (time, geographic space and spectral space).

- Time is discretized by a simple constant time step $\Delta t$ for the simultaneous integration of the propagation and the source terms. 
- Geographic space is discretized by the rectangular grid with constant resolutions $\Delta x$ and $\Delta y$ in $x$ and $y$ direction respectively.

- The spectrum in the model is discretized by the constant directional resolution $\Delta \theta$ and a constant relative frequency resolution $\Delta \sigma / \sigma$.

\section{a. Propagation procedure}

The implicit upwind schemes in both geographic and spectral space, supplemented by a central approximation in spectral space have been used for the propagation procedure. The wave components in the model are correspondingly propagated in geographic space with an upwind scheme in three options:

First-order backward space, backward time scheme,

Second-order upwind scheme with second-order diffusion which is called the SORDRUP scheme and

Second-order upwind scheme with third-order diffusion is uses for non-stationary large scale applications ( $S \& L$ scheme).

\section{b. Curvi-linear grid}

The propagation scheme in SWAN for geographic space is formulated on curvi-linear geographic grid or on the recti-linear grid. For the first grid the distribution of the energy density is approximated between each three neighboring grid points with a flat triangle.

\section{c. Boundary conditions}

The boundary conditions in SWAN, both in geographic space and spectral space are fully absorbing for wave energy that is leaving the computational domain or crossing a coast line. The user will give the incoming wave energy along the open geographic boundaries. For specific coastal regions, the boundary condition is often provided along the open sea boundary and not along the lateral boundary. In order to avoid the error propagated from the lateral boundaries, the computation domain have been chosen so that the area of interest should be sufficiently far away from the lateral boundaries.

\subsection{Input and output files}

The input files have been used in SWAN with the following information:

- a file containing the instruction of the user to the model (the command file),

- files containing: bottom, current, friction, and wind and

- files containing the wave field at the model boundaries (if relevant).

The instructions of the user to control output are separated into three categories:

- Definitions of the geographic locations of the output.

- Times for which the output is requested (for non-stationary cases)

- Type of output quantities (wave parameters, currents etc.) 


\section{SWAN MODEL PERFORMANCE FOR THE STORM MUIFA}

\subsection{Bathymetry and modeling grid}

The grid for storm wave modeling is $0.25^{0}$ latitude and $0.25^{0}$ longitude with the integration domain extending from $-1^{0} \mathrm{~N}$ to $23^{0} \mathrm{~N}$ and $99^{0} \mathrm{E}$ to $119^{\circ} \mathrm{E}(97 \times 81$ grid points according to latitude and longitude respectively). This grid is identical to the grid of SEAMOS organization, which provides the daily fields of analysis waves for the East Sea region and we will use this data for comparing the model results of simulating wave fields of the storm in the following part. Depths were developed from nautical maps of the East Sea and neighbor seas with the accuracy of $0.1 \mathrm{~m}$. The wave spectrum is discretized by 40 frequencies that are logarithmically spaced from $0.0459 \mathrm{~Hz}$ to $1.0 \mathrm{~Hz}$ at intervals of $\Delta f / f=0.1$. The wave propagation directions are 72 with the span of $360^{\circ}$ in $5^{0}$ increments. The maximum chosen number of iterations was 15 for one and three hours computation steps with non-stationary modes. The wind forcing fields is the sea water surface winds provided by JMA at 6-hourly intervals. These wind data, initially on a 1.25 degree grid resolution, was then interpolated onto the above mentioned storm computational grid by specialists from NCHMF.

\subsection{Initial and boundary conditions}

The initial spectra were computed from the local wind velocities, using the deep-water growth curve of Kahma and Calkoen (1992); cut off at values of significant wave height and peak frequency from Pierson and Moskowitz (1964) [3].

In the computation grid, there are two open geographic boundaries as Taiwan and Bashi straits. In order to give the incoming wave energy along the straits at each computation steps, the wave parameters for each incoming direction coincided with wind direction, were computed from the fetch and wind velocities by the same methods as for the initial conditions. The boundary condition of the strait Taiwan and Bashi were obtained before SWAN running and have been stored in specific files.

\subsection{The storm Muifa information and collected data}

Muifa (storm number four in Vietnam ranking for the year 2004) was first declared in the Pacific Ocean, east of Philippines near $134^{\circ} \mathrm{E}, 11^{0} \mathrm{~N}$ on 14 November 2004. The storm increased it's strength and passed the longitude $120^{\circ} \mathrm{E}$ at $06 \mathrm{~h}$ GMT 20 November to the East Sea with the maximum sustained wind speed of $30 \mathrm{~m} / \mathrm{s}$. It later passed the longitude $110^{\circ} \mathrm{E}$ at $18 \mathrm{~h}$ GMT 23 November and then began to turn to South-West direction along the Mekong river coastal line. Fig. 1 shows the path of the storm. On 26 November, the storm hit Malaysia near $100^{\circ} \mathrm{E}, 9.5^{\circ} \mathrm{N}$ and turned northward with gradual decreasing intensity. During the above mentioned period of the time, a heavy North-East monsoon was predominated in the East Sea gained the most severe wind and wave from 18 to 21 November 2004.

The data collected during the occurrence of the storm consist of wave measurement (by wave recorder) at the VietsovPetro oil platform MSP1 $\left(107.98^{0} \mathrm{E}, 9.77^{0} \mathrm{~N}\right)$. Parallely to the data collecting at the fixed stations, the wave analyzed maps from SEAMOS were obtained from internet in order to compare the wave height distribution over the whole area of the sea. 


\subsection{The model execution}

The SWAN model has many parameters that may be adjusted by the modeler to get the best suited to the field measurement results. To accomplish the goal of model calibration for the storm situation, some model runs were performed using different thirdgeneration mode formulations in.wind input and white capping mechanisms. In the thirdgeneration mode, two mechanisms of wave growth by wind and dissipation of wave energy by white capping are adjusted in the paper. The Janssen formulation had two coefficients: the coefficient for determining rate of dissipation (CDS1) and the one for determining the dependency of white capping on wave number (DELTA). The Komen formulation for wave growth contains a coefficient to determine rate of dissipation (CDS2) and a coefficient determining the value of wave steepness for a Pierson-Moskowitz spectrum (STPM). The other mechanism had been chosen to evaluate is the friction effect by the bottom. To determine the bottom friction, the semi-empirical expression derived from JONSWAP results for bottom friction dissipation was used for swell condition and wind condition. The wave growth terms of Cavaleri and Malanotte also has been evaluated.

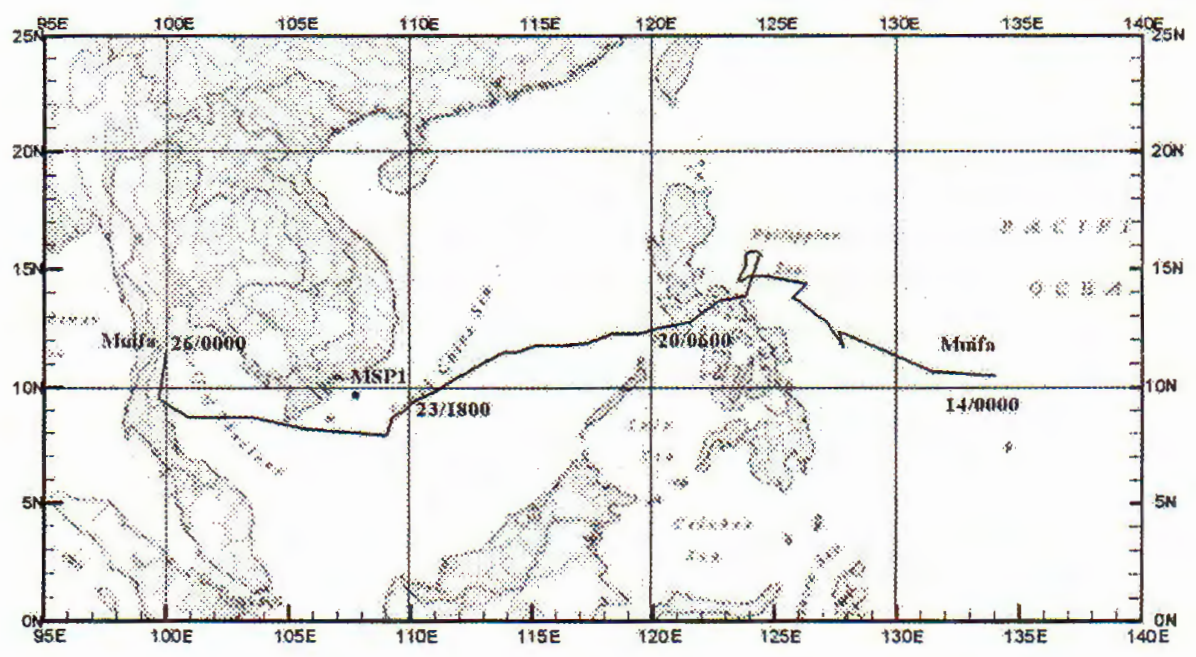

Fig. 1. Path of Muifa 11/2004

For the mentioned formulations of physical processes, the SWAN was executed with

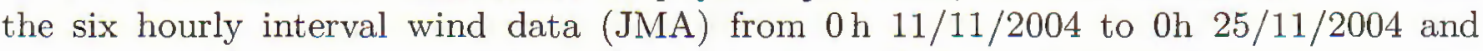
appropriated boundary conditions. Two time steps of one and three hours were chosen. The out put results (wave parameters and spectral energy) were recorded at every grid points and at the MSP1 location.

\section{COMPUTATION RESULTS AND DISCUSSION}

Two sets of obtained results are available to compare themselves and with the collected data. They are the time varying of wave parameters at the specific location and their spatial distribution over the East Sea.

Fig. 2 depicts the results of 4 SWAN runs for different physical formulations of Janssen and Komen and different friction coefficients of wind wave and swell at the MSP1 location. It is showed that the friction coefficients of wind wave or swell do not change so much the 
wave heights and periods. On the other hand, the formulations of Janssen and Komen produce different wave heights especially for the peaks values (see the Fig. 2a) although the general tendency of time varying of the parameters are the same.
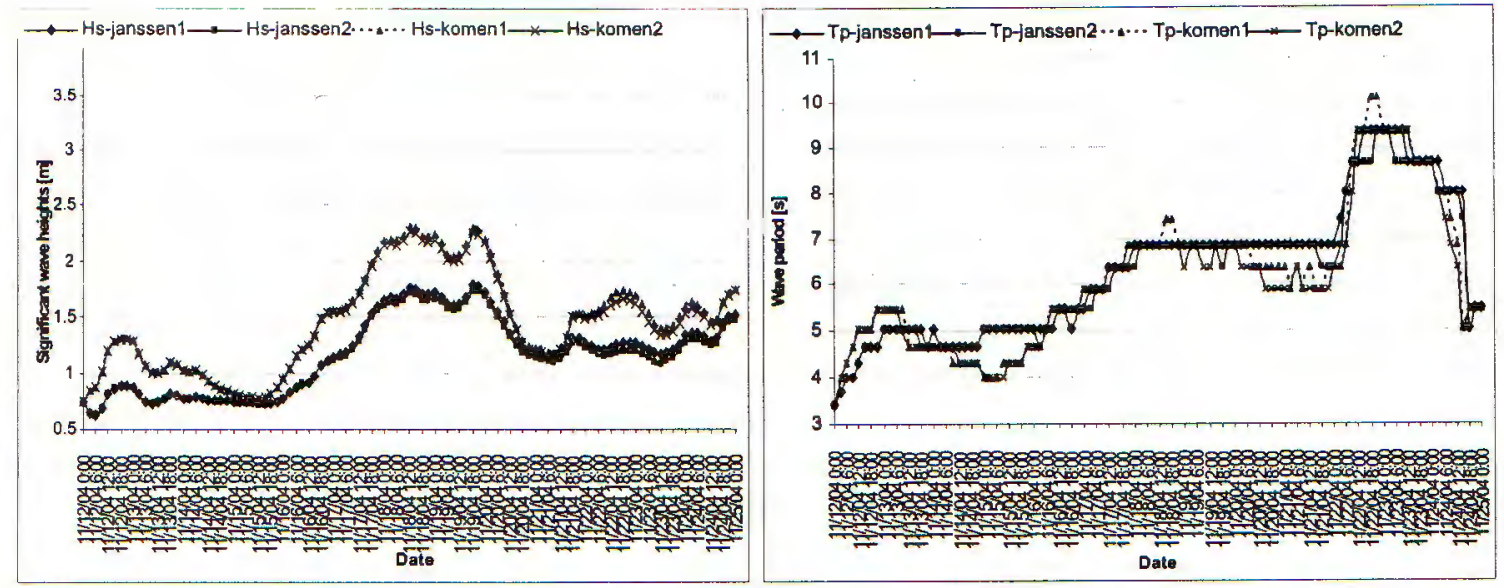

Fig. 2. Wave height (a) and period (b) computed by Janssen and Komen different plysical formulations and different friction coefficients of wind wave and swell at the MSP1 location: Janssen1: CDS1=4.5; Delta=0.5; Friction Jonswap 0.038 QUADRUPL AGROW 0.0015 - Janssen2: CDS1 $=4.5$; Delta=0.5; Friction Jonswap 0.067 QUADRUPL AGROW 0.0015 - Komen1: CDS2=0.000236; stpm=0.00302; Friction Jonswap 0.038 QUADRUPL AGROW 0.0015 - Komen2: CDS2=0.000236; stpm $=0.00302$; Friction Jonswap 0.067 QUADRUPL AGROW 0.0015

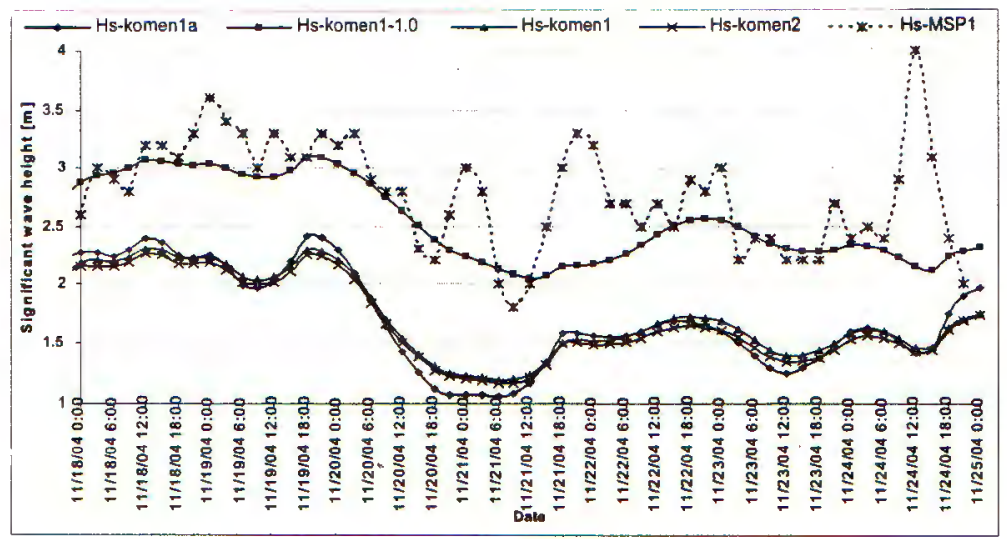

Fig. 3. The time-histories of the computed wave heights with different coefficients of dissipation (CDS2) and the wave growth terms and measured values from $0 \mathrm{~h} 18 / 11$ to $0 \mathrm{~h} 25 / 11$ at the MSP1, during the storm Muifa: Komen1a: $\mathrm{CDS} 2=0.000236$; stpm $=0.00302$; QUADRUPL AGROW 0.15; Friction Jonswap 0.038 - Komen1-1.0: CDS2 $=0.0001$; stpm=0.00302; QUADRUPL AGROW 0.0015; Friction Jonswap 0.038 - Komen1: CDS2 $=0.000236$; stpm $=0.00302$; QUADRUPL AGROW 0.0015; Friction Jonswap 0.038 - Komen2: CDS2 $=0.000236$; stpm=0.00302; QUADRUPL AGROW 0.0015 ; Friction Jonswap 0.067 


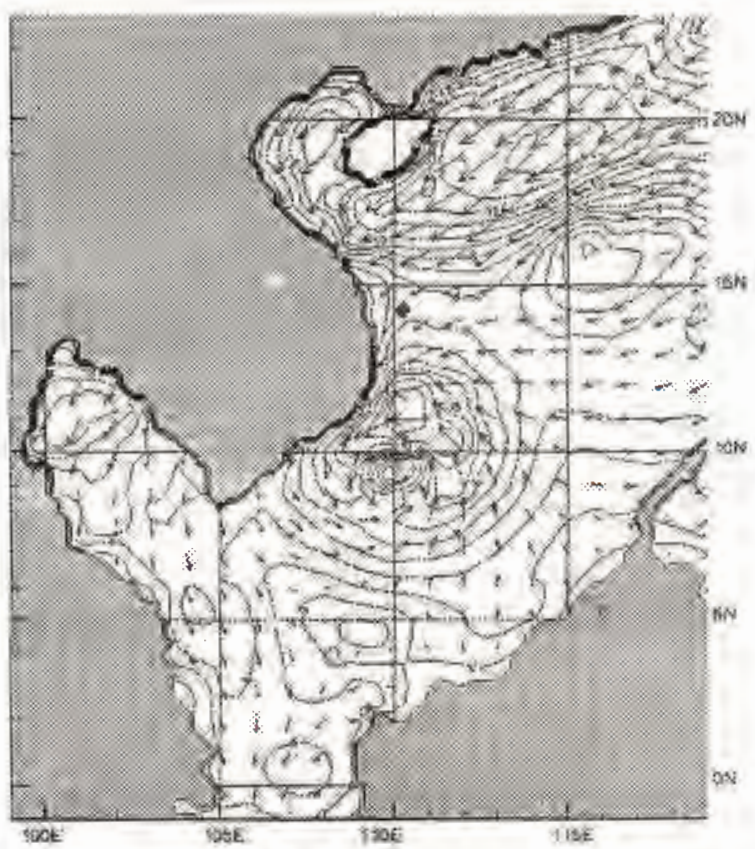

Fig. 4. The JMA's wind field for 0 h $24^{\text {th }}$ November 2004

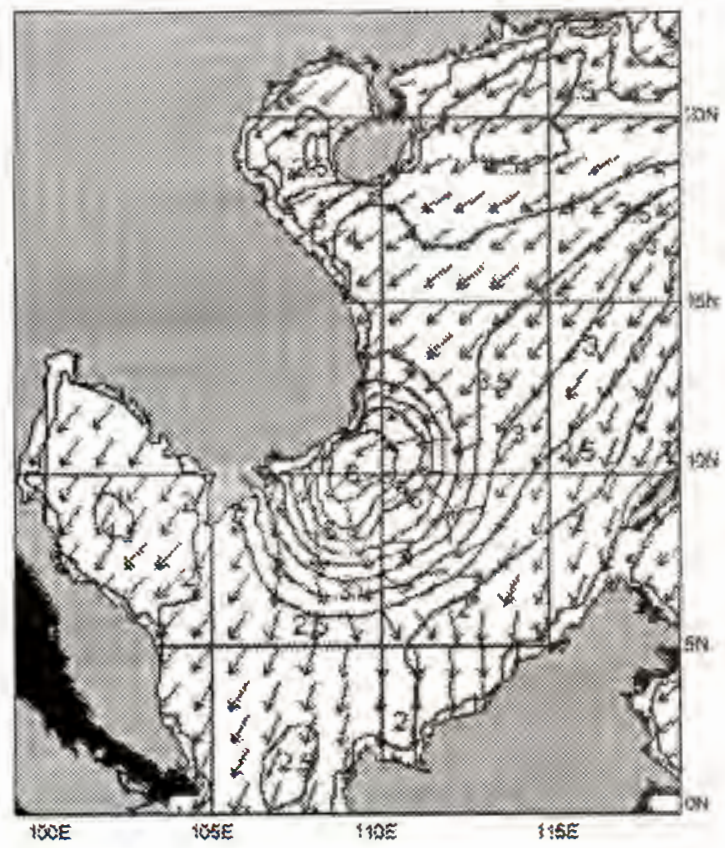

Fig. 5. Significant wave height from SEAMOS for $0 \mathrm{~h} 24^{\text {th }}$ November 2004

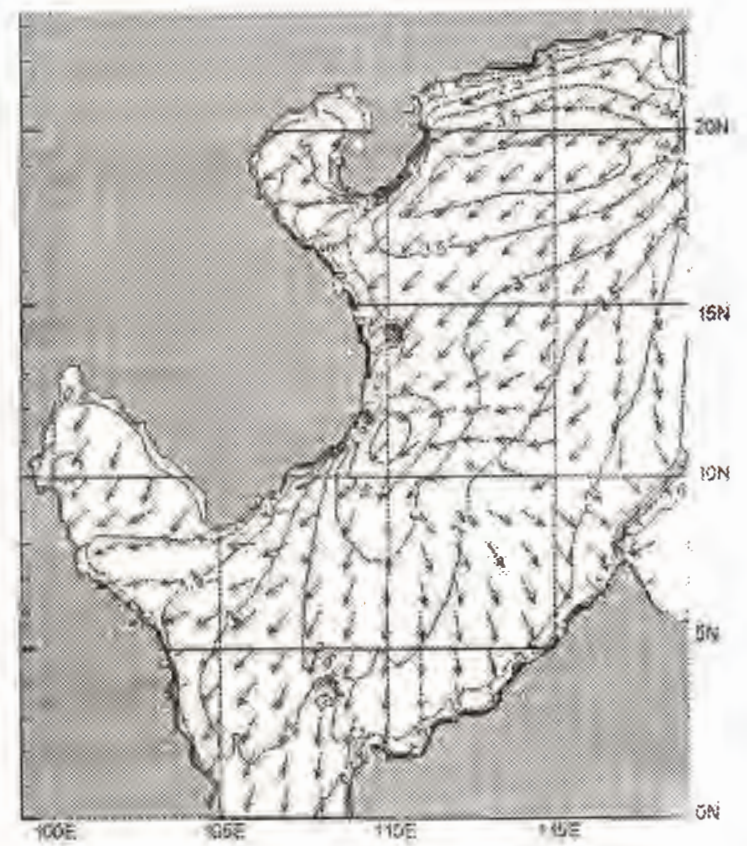

Fig. 6. Computed significant wave height for $0 \mathrm{~h} 24^{\text {th }}$ November 2004 
The Komen formulation is more sensitive with the wave growth and it always produces higher wave heights, the maximum differences are about half meter during the severe wave condition (from $18^{\text {th }}$ to $20^{\text {th }}$ of November, see Fig. 2a).

The differences in wave periods are less in comparing with wave heights. Taking in the consideration that SWAN tends to underestimate the wave heights [2], the Komen formulation was used for further calibration with the field measurement. Fig. 3 shows the time-histories of the computed wave heights with different coefficients of dissipation

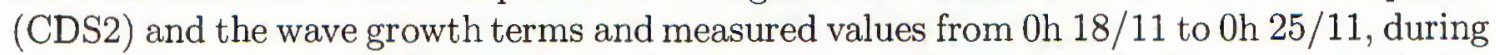
the storm Muifa in the East Sea. All the principle coefficients of the Komen formulation and a new coefficient of the wave growth term (increasing the value of the coefficient " $a$ " by two order of magnitude $-a=0.15$ ) are under predicted. The better agreement with the field measurement at MSP1 is the SWAN run with the coefficient CDS2 equal to $0.1 \times 10^{-4}$ - near the half of principle value $\left(0.236 \times 10^{-4}\right)$. The short time disturbances of measured wave height was attributed to the local wind activities which could not be formulated in the wind data of JMA. Fig. 4 demonstrates the forcing wind for Oh GMT of 24 November obtained from JMA, the computed and analyzed (from SEAMOS) wave fields are shown in the Figs. 5 and 6. Both the model and analyzing indicate a zone of maximum significant wave height off shore of Ninh Thuan province although the analyzed maximum is a bit greater than computed one. For the overall wave field in the East Sea, the computed results agree reasonably well with the analyzed field.

\section{CONCLUSIONS}

The SWAN model was used to calculate wave parameters for the storm MUIFA $11 / 2004$. By varying some of the physical processes formulations of Janssen and Komen, the most important coefficients for accurate model calibration were determined. While the sensitivity of the model not depends so much on friction coefficients of wind wave or swell, formulations for energy dissipation due to white capping play important role on modeling wave height. In the Komen formulation, the effect of this energy dissipation is greater than the Janssen formulation so it was chosen for further evaluation. The better agreement with the field measurement at MSP1 is the SWAN run with the double decreased of the coefficient CDS2. Spatial patterns in significant wave height in the storm computed by SWAN agree reasonably well with the analyzed wave height field from SEAMOS.

This study was funded by the project VS/RDE/03 "the evolution and sustainable management in the coastal areas of Vietnam" which is provided at the Center for Marine Environment Survey, Research and Consultation (CMESRC), Institute of Mechanics. The study also partly supported by the Basic Research Program, Project: Marine Hydrodynamics and Environment for 2004-2005, code number 321501. The authors thank Mr. Vo Van That, the head engineer from Vietsov-Petro for the wave data at the MSP-1 oil platform.

\section{REFERENCES}

1. Coastal Engineering Manual, Department of the Army, U.S. Army Corps of Engineers, Washington, DC 9/2001.

2. Margaret L. Palmsten, Application of the Swan Wave Model to a High-Energy Continental Shelf, University of South Florida, 2001, 33-127. 
3. Swan - User Manual Swan Cycle III Version 40.41, Delft University of Technology, 2005.

Received October 3, 2005

Revised November 15, 2005

\section{TÍNH SÓNG TRONG BÃO BẰNG MÔ HÌNH SWAN SO SÁNH KẾT QUẢ TÍNH TOÁN VÀ SỐ LIỆU DO DẠC TRONG BĀO MUIFA 11/2004}

Sóng trong bão là một trong những tham số khí tượng thuỷ văn cực kỳ nguy hiểm đối với mọi công trình xây dựng ven bờ và công trình bảo vệ bờ biển. Bài báo nhằm phục vụ cho việc giảm nhẹ thiên tai trong bão, nâng cao hiệu quả của công tác dự báo sóng trong bão và phục vụ nghiên cứu biến đổi bờ biển vùng châu thổ sông Hồng. Các tác giả đã tính toán trường sóng trong bão Muifa - số 4 năm 2004, sử dụng mô hình SWAN với các cơ chế vật lý khác nhau của các quá trình sóng đổ bạc đầu và các quá trình tiêu hao năng lượng sóng do đáy biển đối với sóng gió và sóng lừng. Các kết quả tính toán được so sánh với các số liệu tự ghi sóng tại giàn khoan Bạch Hổ MSP1 và số liệu trường sóng của Chương trình Nghiên cứu Khí tượng Hải dương SEAMOS. Kết quả cho thấy sử dụng cơ chế tương tác và tiêu hao năng lượng của Komen với hệ số tiêu hao do sóng bạc đầu giảm 2 lần so với giá trị mặc định cho các kết quả trường sóng trong bão phù hợp nhất với số liệu do đạc thực tế. 